archives

of thermodynamics

Vol. 37(2016), No. 1, 127-142

DOI: 10.1515/aoter-2016-0009

\title{
Numerical simulation of thermal-hydraulic processes in the riser chamber of installation for clinker production
}

\author{
GRZEGORZ BORSUK ${ }^{a}$ \\ BOLESEAW DOBROWOLSKI ${ }^{a}$ \\ GRZEGORZ NOWOSIELSKI ${ }^{a}$ \\ JACEK WYDRYCH ${ }^{a 1}$ \\ JERZY DUDA ${ }^{b}$
}

a Opole University of Technology, Department of Thermal Engineering and Industrial Facilities,Prószkowska 76, 45-758 Opole, Poland

${ }^{b}$ Opole University of Technology,Department of Innovative Processes, Prószkowska 76, 45-758 Opole, Poland

\begin{abstract}
Clinker burning process has a decisive influence on energy consumption and the cost of cement production. A new problem is to use the process of decarbonization of alternative fuels from waste. These issues are particularly important in the introduction of a two-stage combustion of fuel in a rotary kiln without the typical reactor-decarbonizator. This work presents results of numerical studies on thermal-hydraulic phenomena in the riser chamber, which will be designed to burn fuel in the system where combustion air is supplied separately from the clinker cooler. The mathematical model is based on a combination of two methods of motion description: Euler description for the gas phase and Lagrange description for particles. Heat transfer between particles of raw material and gas was added to the numerical calculations. The main aim of the research was finding the correct fractional distribution of particles. For assumed particle distribution on the first stage of work, authors noted that all particles were carried away by the upper outlet to the preheater tower, what is not corresponding to the results of experimental studies. The obtained results of calculations can be the basis for further optimization of the design and operating conditions in the riser chamber with the implementation of the system.
\end{abstract}

Keywords: Two-phase flow; Precalcination; Particle distribution; CFD

\footnotetext{
${ }^{1}$ Corresponding Author. E-mail: j.wydrych@po.opole.pl
} 


\section{Nomenclature}

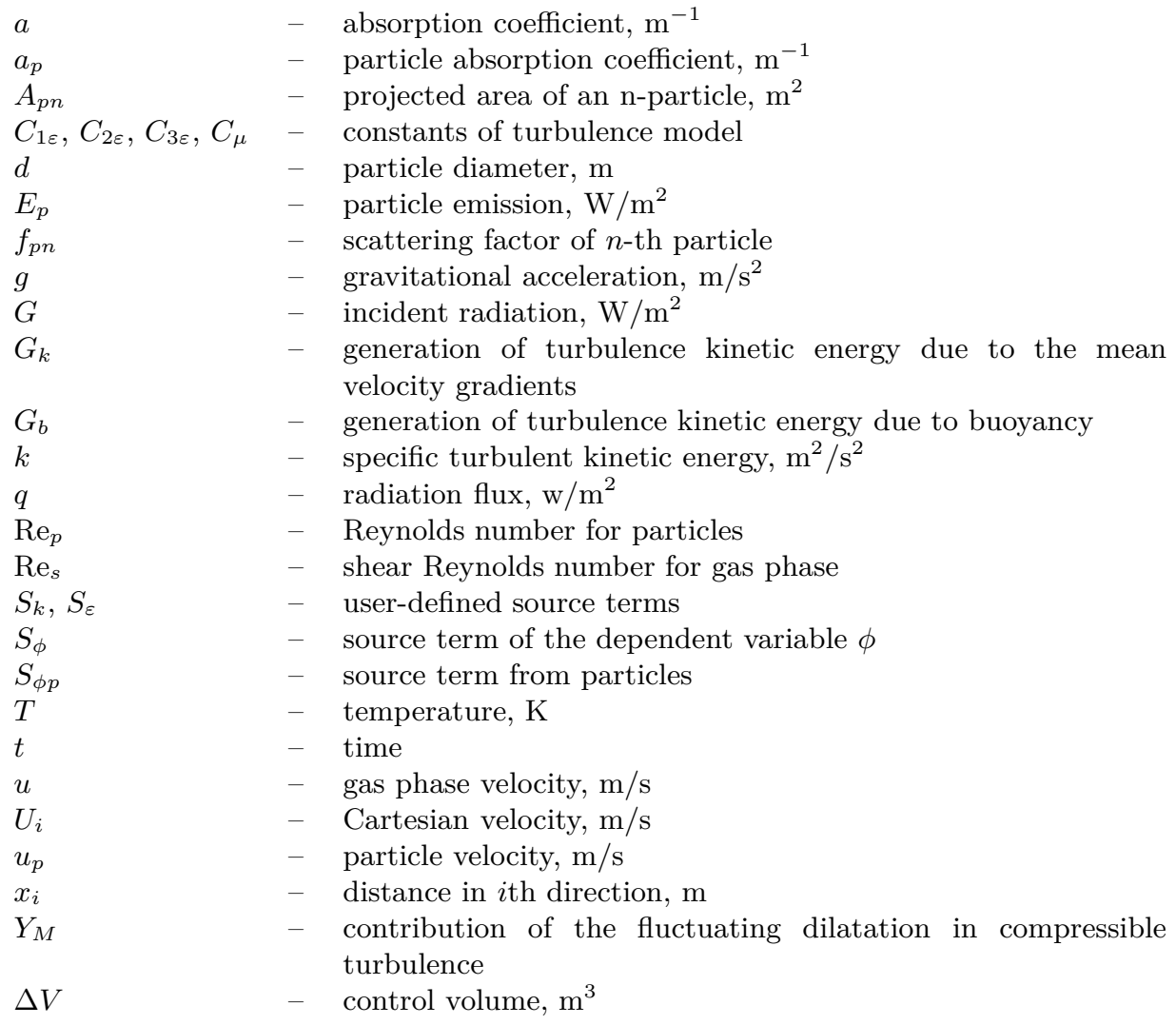

\section{Greek symbols}

$\Gamma \quad-\quad$ diffusion coefficient, $m$

$\Gamma_{\phi} \quad-\quad$ coefficient of diffusion transport of the dependent variable $\phi$

$\varepsilon \quad-$ turbulent kinetic energy dissipation rate, $\mathrm{m}^{2} / \mathrm{s}^{3}$

$\epsilon_{p n} \quad-\quad$ emissivity of $n$th particle

$\mu \quad-\quad$ dynamic viscosity, Pas

$\mu_{t} \quad-\quad$ eddy viscosity, Pas

$\rho \quad-$ gas phase density, $\mathrm{kg} / \mathrm{m}^{3}$

$\sigma \quad-$ Stefan-Boltzmann's constant, $\mathrm{W} /\left(\mathrm{m}^{2} \mathrm{~K}^{4}\right)$

$\sigma_{k}, \sigma_{\varepsilon} \quad-$ turbulent Prandtl numbers for $k$ and $\epsilon$

$\sigma_{p} \quad-$ particle scattering factor, $\mathrm{m}^{-1}$

$\tau_{p} \quad-\quad$ particle relaxation time, $\mathrm{s}$

$\phi \quad-$ generalized dependent variable

$\omega \quad-\quad$ angular velocity of the particles, $1 / \mathrm{s}$

$\nabla \quad-$ gradient operator

A right arrow over letter denote a vector. 


\section{Introduction}

Industrial installations for clinker production have a very complex structure and they are difficult to analyses by theoretical methods [1]. One of the most important elements of this installation is precalciner, where is the initial stage of the raw material calcination $[2,3]$. After being prepared, the row mixture goes into the pyroprocessing system. This system consists of a preheater tower, a calciner and a dry rotary kiln. The raw meal is fed in at the top of the preheater tower and passes through the series of cyclones in the tower. Hot gas from the kiln and, often, hot air from the clinker cooler are blown through the cyclones. Heat is transferred efficiently from the hot gases to the raw meal. The main part of the work is modeling the phenomena flow in the chamber with a typical construction. Gas-particle multiphase flow in some kind of precalcination chamber is considered. The particle size distribution in inlets to precalciner chamber has an influence on heat and mass transfer between particles and gas. As a result of sieve analysis of raw material and Rosin-Rammler-Sperling calculation method [4], authors obtained a particle size distribution and this was assumed in the early stage of calculations. The Euler-Lagrange description is used for many different flow problems from large to small objects [5-8]. Due to Euler-Lagrange description used for the calculation, it was necessary to set the correct fractional distribution of particles. For assumed particles distribution, authors noticed that all particles were carried away by an upper outlet to the preheater tower. Sieve analysis was made for particles after cooling to room temperature. This situation creates a risk that during the sieving process particle were crushed and sieve residues do not represent the fractional composition of raw material in a real flow. The possibility of particles coagulation increases with the temperature. Because of that, particles from cyclones IV may have larger diameters than those from cyclones III. The authors proposed a method based on the increase of the upper range of particle diameters. Because of the impossibility to determine the true particles size distribution by measurements, therefore authors used the method of gradually increasing particle diameters [9]. Thermalhydraulic processes in precalciner installation are presented in the following parts of the work. Presented results are first stage works on the formation and emission of pollutants especially $\mathrm{NO}_{x}$ and $\mathrm{CO}_{2}$ to the atmosphere. 


\section{Method of calculations}

In order to realize numerical calculations, the mathematical model containing equations of motion for the gaseous phase and particles was formulated. The gas motion was described with the Euler description, and the particle motion - by the Lagrange description. To analyze the motion of the gasparticle polydispersive mixture, in this paper the method was applied of the particle source in cell (PSI-Cell) [10-12].

Numerical calculations are based on the following assumptions: considered flow is stationary, without phase changes, and both phases are incompressible. Gas motion is described in the uniform, generalized conservative form, isolating convection, diffusion and source components. In a consequence we obtain

$$
\frac{\partial(\rho \phi)}{\partial t}+\frac{\partial\left(\rho U_{i} \phi\right)}{\partial x_{i}}=\frac{\partial}{\partial x_{i}}\left(\Gamma_{\phi} \frac{\partial \phi}{\partial x_{i}}\right)+S_{\phi}+S_{\phi p},
$$

where $\phi$ is a generalized dependent variable, $\Gamma_{\phi}$ is the coefficient of diffusion transport, and the source term $S_{\phi}$ contains all the remaining components of the differential equations [10]. The coefficients $\Gamma_{\phi}$ and $S_{\phi}$ are dependent on the variable $\phi$. The fundamental equations of continuum mechanics are based on the conservation laws for mass, momentum, and energy. In the PSI-Cell method, it is assumed that particles of the disintegrated phase are the sources of mass, momentum and energy occurring as additional components $S_{\phi p}$ in equations of the continuous (gaseous) phase.

The system of equations is accompanied by suitable boundary and initial conditions. This system of partial differential equations is nonlinear. Particular equations are coupled, so they have to be solved with special numerical techniques.

In order to calculate turbulence, the $k$ - $\varepsilon$ model was used. The standard $k-\epsilon$ model is a semiempirical model based on model transport equations for the turbulence kinetic energy $k$ and its dissipation rate $\varepsilon$. The exact $k-\varepsilon$ equations contain many unknown and unmeasurable terms. The much more practical approach, the standard $k-\varepsilon$ turbulence model is used which is based on the best understanding of the relevant processes, thus minimizing unknowns and presenting a set of equations which can be applied to a large number of turbulent applications [13]. In the derivation of the $k-\varepsilon$ model, it was assumed that the flow was fully turbulent, and the effects of molecular viscosity were negligible. The standard $k-\varepsilon$ model is therefore only valid for fully turbulent flows [3]. The turbulence kinetic energy, $k$, and its rate of 
dissipation, $\varepsilon$, are calculated from the following transport equations [14]:

$$
\begin{gathered}
\frac{\partial}{\partial t}(\rho k)+\frac{\partial}{\partial x_{i}}\left(\rho k u_{i}\right)=\frac{\partial}{\partial x_{j}}\left[\left(\mu+\frac{\mu_{t}}{\sigma_{k}}\right) \frac{\partial k}{\partial x_{j}}\right]+G_{k}+G_{b}-\rho \varepsilon-Y_{M}+S_{k} \\
\frac{\partial}{\partial t}(\rho \varepsilon)+\frac{\partial}{\partial x_{i}}\left(\rho \varepsilon u_{i}\right)= \\
=\frac{\partial}{\partial x_{j}}\left[\left(\mu+\frac{\mu_{t}}{\sigma_{\varepsilon}}\right) \frac{\partial \varepsilon}{\partial x_{j}}\right]+C_{1 \varepsilon} \frac{\varepsilon}{k}\left(G_{k}+C_{3 \varepsilon} G_{b}\right)-C_{2 \varepsilon} \rho \frac{\varepsilon^{2}}{k}+S_{\varepsilon} .
\end{gathered}
$$

In these equations, $G_{k}$ represents the generation of turbulence kinetic energy due to the mean velocity gradients, $G_{b}$ is the generation of turbulence kinetic energy due to buoyancy. $Y_{M}$ represents the contribution of the fluctuating dilatation in compressible turbulence to the overall dissipation rate, $C_{1 \varepsilon}, C_{2 \varepsilon}$, and $C_{3 \varepsilon}$ are constants. $\sigma_{k}$ and $\sigma_{\epsilon}$ are the turbulent Prandtl numbers for $k$ and $\varepsilon$, respectively. $S_{k}$ and $S_{\epsilon}$ are user-defined source terms. The turbulent (or eddy) viscosity $\mu_{t}$ is computed by combining $k$ and $\varepsilon$ as follows:

$$
\mu_{t}=\rho C_{\mu} \frac{k^{2}}{\varepsilon} .
$$

The model constants have the following default values: $C_{1 \varepsilon}=1.44, C_{2 \varepsilon}=$ $1.92, C_{\mu}=0.09, \sigma_{k}=1.0$ and $\sigma_{\varepsilon}=1.3$.

The particle trajectory should be known during calculation of the mentioned above source components of differential equations. The particle trajectory is calculated according to its equation of motion [14]. If the phase density difference is large, the equation of particle motion can be written as

$\frac{d \vec{u}_{p}}{d t}=\frac{1}{\tau_{p}}\left(\vec{u}-\vec{u}_{p}\right)+g+3.084\left(\frac{\mu}{\rho}\right)^{1 / 2}\left(\frac{1}{|\vec{\omega}|}\right)^{1 / 2}\left\{\vec{\omega} \times\left(\vec{u}-\vec{u}_{p}\right)\right\} f\left(\operatorname{Re}_{p}, \operatorname{Re}_{s}\right)$.

The right part of the equation includes the shear lift force determined on the basis of Saffman's analytical considerations. The local velocity of the gas is determined by

$$
\vec{\omega}=\frac{1}{2} \nabla \times \vec{u},
$$

while a factor $f\left(\operatorname{Re}_{p}, \operatorname{Re}_{s}\right)$ is described by the relationship

$$
\begin{array}{r}
f\left(\operatorname{Re}_{p}, \operatorname{Re}_{s}\right)=\left(1-0.3314 \beta^{1 / 2}\right) \exp \left(-\frac{\operatorname{Re}_{p}}{10}\right)+0.3314 \beta^{1 / 2} \\
\text { for } \operatorname{Re}_{p} \leq 40,
\end{array}
$$


or

$$
f\left(\operatorname{Re}_{p}, \operatorname{Re}_{s}\right)=0.0524\left(\beta \operatorname{Re}_{p}\right)^{1 / 2} \text { for } \operatorname{Re}_{p}>40
$$

where

$$
\beta=\frac{1}{2} \frac{\operatorname{Re}_{s}}{\operatorname{Re}_{p}} .
$$

The trajectory equations, and any auxiliary equations describing heat or mass transfer to/from the particle, are solved by stepwise integration over discrete time steps. Integration of time in equation yields the velocity of the particle at each point along the trajectory, with the trajectoty itself predicted by:

$$
\frac{d \vec{x}}{d t}=\vec{u}_{p} .
$$

The radiative heat transfer and the effects of particle radiation from the limestone particles are modeled with the P-1 radiation model [14-16]:

$$
\nabla(\Gamma \nabla G)=\left(a+a_{p}\right) G-4 \pi\left(a \frac{\sigma T^{4}}{\pi}+E_{p}\right),
$$

where the term on the left hand side represents the change of the incident radiation. The first term on the right hand side represents the absorption, from the continuous phase and the particles, and the second term on the right hand side represents the emission, again from the continuous phase and the particles. For the particle emission $E_{p}$ the following correlation is used:

$$
E_{p}=\frac{1}{\Delta V} \sum_{n=1}^{N} \varepsilon_{p n} A_{p n} \frac{\sigma T^{4}}{\pi},
$$

while the particle absorption coefficient is calculated as

$$
a_{p}=\frac{1}{\Delta V} \sum_{n=1}^{N} \varepsilon_{p n} A_{p n},
$$

where $N$ is the amount of particles, and $\Delta V$ is the control volume. The diffusion coefficient, $\Gamma$, is calculated as

$$
\Gamma=\frac{1}{3\left(a+a_{p}+\sigma_{p}\right)},
$$

and for the particle scattering factor, $\sigma_{p}$, the following correlation is used:

$$
\sigma_{p}=\frac{1}{\Delta V} \sum_{n=1}^{N}\left(1-f_{p n}\right)\left(1-\varepsilon_{p n}\right) A_{p n} .
$$


The source term that is directly introduced into the enthalpy equation as a radiative heat source is calculated as follows:

$$
-\nabla q_{r}=-4 \pi\left(a \frac{\sigma T^{4}}{\pi}+E_{p}\right)+\left(a+a_{p}\right) G .
$$

Equations presented above were solved with the using ANSYS Fluent Package [17].

\section{Results}

The outlet from the kiln is the source of gas produced during the combustion of fuel and chemical transformation of raw material in the high temperature. The same cross-section is treated as an outlet for calcined material. Raw material is supplied from two inlets. In the following descriptions, raw material inlets from cyclones III and VI are called upper and lower inlets, respectively, regarding outlets inlet from kiln and outlet to cyclones, are called lower and upper outlets. Fig. 1 presents calculation domain with the information about inlets, outlets, and geometrical shape of the chamber. In order to perform the calculations, authors adopted the boundary conditions, which are shown in Tab. 1.

Table 1: Boundary conditions for inlets and outlets.

\begin{tabular}{|c|c|c|c|}
\hline Boundary & velocity $[\mathrm{m} / \mathrm{s}]$ & Temperature $[\mathrm{K}]$ & Pressure $[\mathrm{Pa}]$ \\
\hline Inlet from kiln & 15 & 1370 & -400 \\
\hline Outlet to bypass & -30 & 1100 & -400 \\
\hline Outlet to cyclones & $\begin{array}{l}\text { From the balance of } \\
\text { the inflow mass }\end{array}$ & 1112 & -800 \\
\hline Coal inlet & 100 & 300 & 0 \\
\hline Shale's inlet & 45 & 300 & 0 \\
\hline Tires inlet & \multicolumn{3}{|c|}{ Closed - treated as a wall } \\
\hline $\begin{array}{l}\text { Raw material inlet from } \\
\text { cyclones III }\end{array}$ & \multirow{2}{*}{$\begin{array}{l}\text { From flow rate of } \\
\text { particles (Tab. 2) }\end{array}$} & 1000 & 0 \\
\hline $\begin{array}{l}\text { Raw material inlet from } \\
\text { cyclones IV }\end{array}$ & & 1100 & 0 \\
\hline
\end{tabular}

Negative pressure in the table means that the system works as the 'vacuum' kiln (negative pressure inside the kiln). It is widely used, because the great 


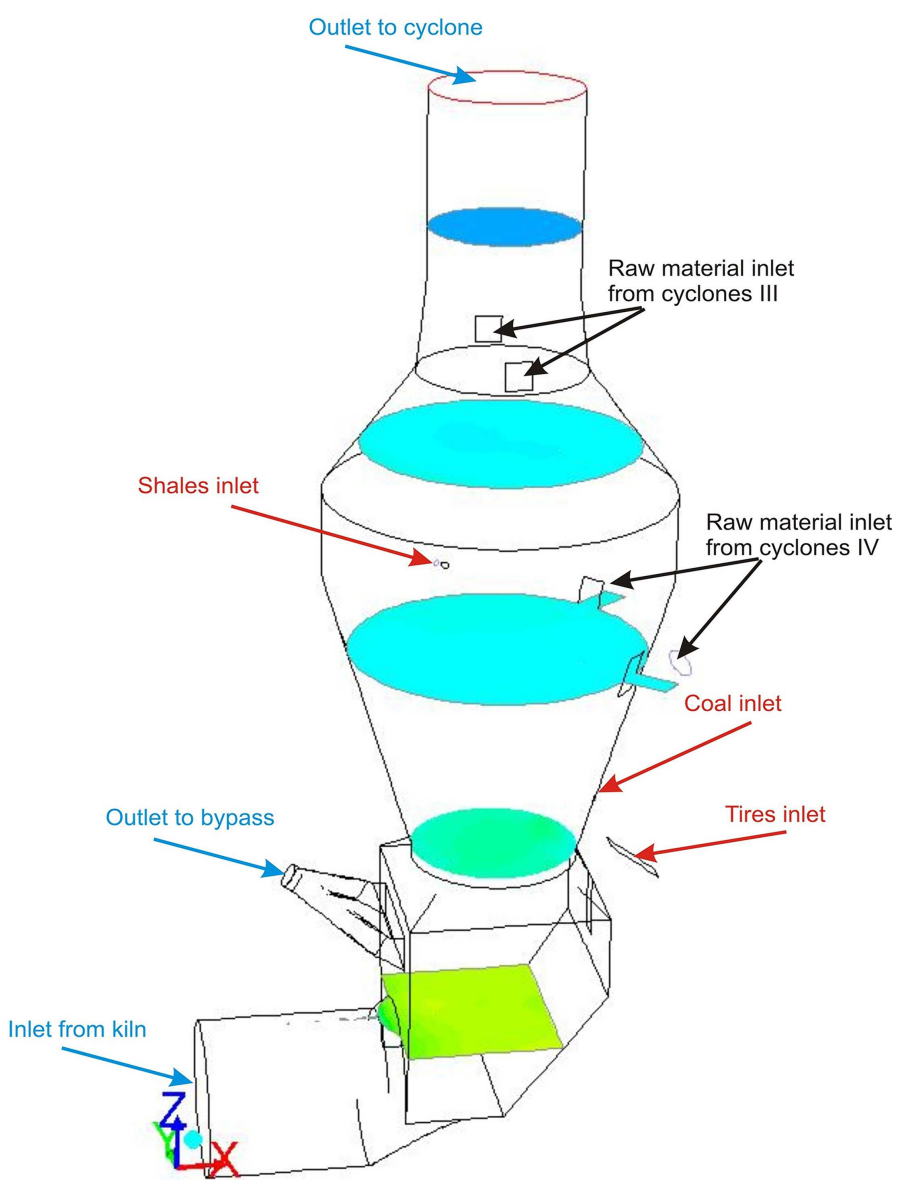

Figure 1: Calculation domain with control cross-sections.

advantage of this solution is its lower price. The particle size distribution in inlets to the precalciner chamber has an influence on heat and mass transfer between particles and gas. As a result of sieve analysis of raw material and Rosin-Rammler-Sperling [4] calculation method, the authors obtained a particle size distribution as shown in Fig. 2. This distribution was assumed in the early stages of calculations.

Due to Euler-Lagrange description used for the calculation, it was necessary to set the correct fractional distribution of particles. For assumed particles distribution, authors noted that all particles were carried away 


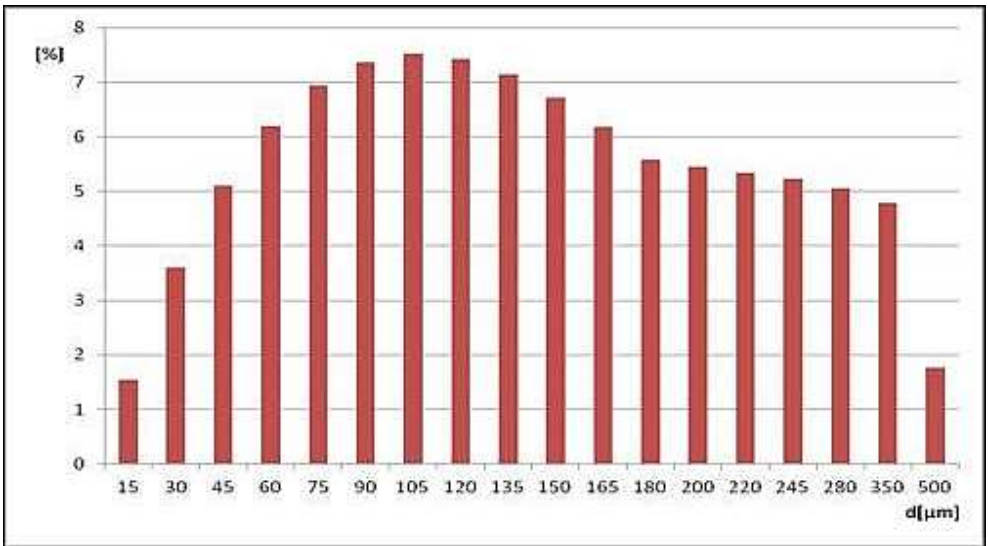

Figure 2: Particle size distributions of raw material.

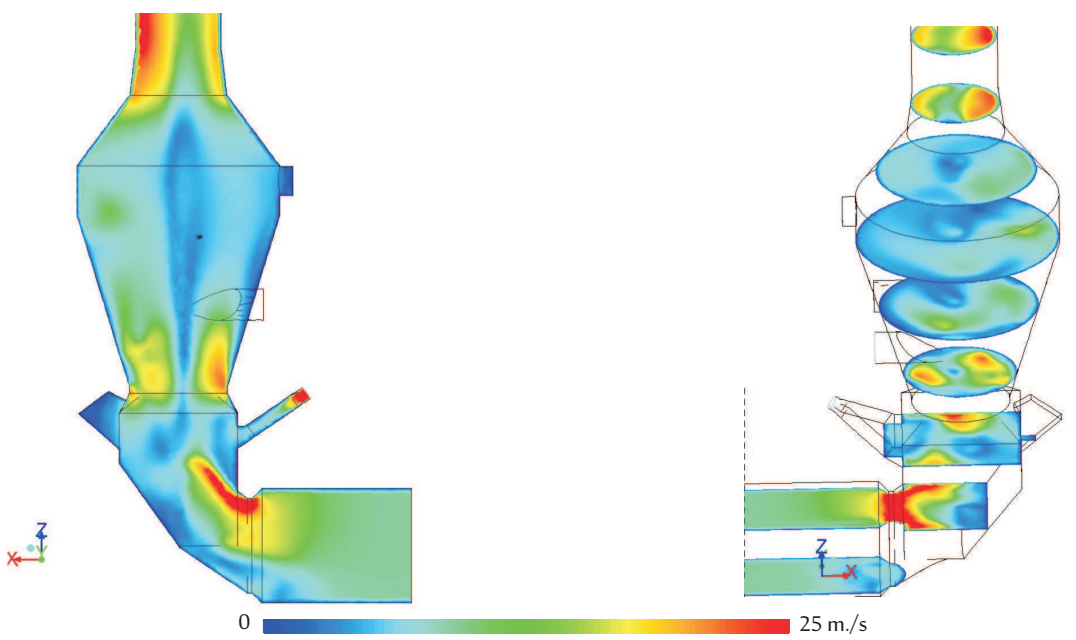

Figure 3: Distribution of velocity magnitude in precalciner chamber.

by an upper outlet to preheater tower (Fig. 1). Sieve analysis, shown in Fig. 2, was made for particles after cooling to room temperature.

Figure 3 presents distributions of the gas velocity modulus in the considered geometry. Due to incorrect particle distribution as a result of sieve analysis of raw material and Rosin-Rammler-Sperling calculation method, to reach from the initial ranges of diameters (basic $d$ in Tab. 2), corresponding to the mass distribution between the upper and lower outlets, about 20 steps in the search for the appropriate range were made. In final series of 
the results, upper limits of the particle diameters from the upper and lower inlets were set to $1500 \mu \mathrm{m}$ and $2900 \mu \mathrm{m}$, respectively. This range was used as a correct for final calculations [9]. From this moment numbering of the particle is related to a basic diameter from the sieve analysis and actual particle diameters for upper and lower inlets as in Tab. 2 [9].

Table 2: Corrected values of particle diameters $(d)$ of raw materialand flow rates $(M)$ for upper $(U)$ and lower $(L)$ inlets.

\begin{tabular}{|c|c|c|c|c|c|}
\hline No. particle & Basic $d[\mu \mathrm{m}]$ & $d_{U}[\mu \mathrm{m}]$ & $M_{U}[\mathrm{~kg} / \mathrm{s}]$ & $d_{L}[\mu \mathrm{m}]$ & $M_{L}[\mathrm{~kg} / \mathrm{s}]$ \\
\hline \hline P01 & 15 & 15 & 0.428 & 15 & 0.385 \\
\hline P02 & 30 & 60 & 1 & 105 & 0.9 \\
\hline P03 & 45 & 105 & 1.417 & 195 & 1.275 \\
\hline P04 & 60 & 155 & 1.722 & 285 & 1.55 \\
\hline P05 & 75 & 200 & 1.928 & 370 & 1.735 \\
\hline P06 & 90 & 245 & 2.047 & 460 & 1.843 \\
\hline P07 & 105 & 290 & 2.089 & 550 & 1.88 \\
\hline P08 & 120 & 335 & 2.064 & 640 & 1.858 \\
\hline P09 & 135 & 380 & 1.986 & 730 & 1.788 \\
\hline P10 & 150 & 430 & 1.867 & 820 & 1.68 \\
\hline P11 & 165 & 475 & 1.717 & 905 & 1.545 \\
\hline P12 & 180 & 520 & 1.55 & 995 & 1.395 \\
\hline P13 & 200 & 580 & 1.794 & 1115 & 1.615 \\
\hline P14 & 220 & 645 & 1.486 & 1235 & 1.338 \\
\hline P15 & 245 & 720 & 1.456 & 1385 & 1.31 \\
\hline P16 & 280 & 825 & 1.406 & 1590 & 1.265 \\
\hline P17 & 350 & 1040 & 1.331 & 2010 & 1.198 \\
\hline P18 & 500 & 1500 & 0.492 & 2900 & 0.443 \\
\hline
\end{tabular}

By scaling the particle diameters we can observe, that the mass flow rate reaching directly to the kiln and returning to the heat exchangers tower was significantly changed. After changing the range of diameters to $15-2900 \mu \mathrm{m}$, large diameter particles fall into the rotary kiln, while the remaining fractions are carried away to the outlet from the chamber.

Figure 4 presents temperature distribution in the precalciner chamber for two ranges of temperature. Figure 5 shows the results of particle trajectory calculations delivered to the system from the upper and lower inlets for particles P03, P18 and for all consider particles. Analysis of Fig. 5 lead to the conclusion that the largest particles end up in the lower outlet, the 

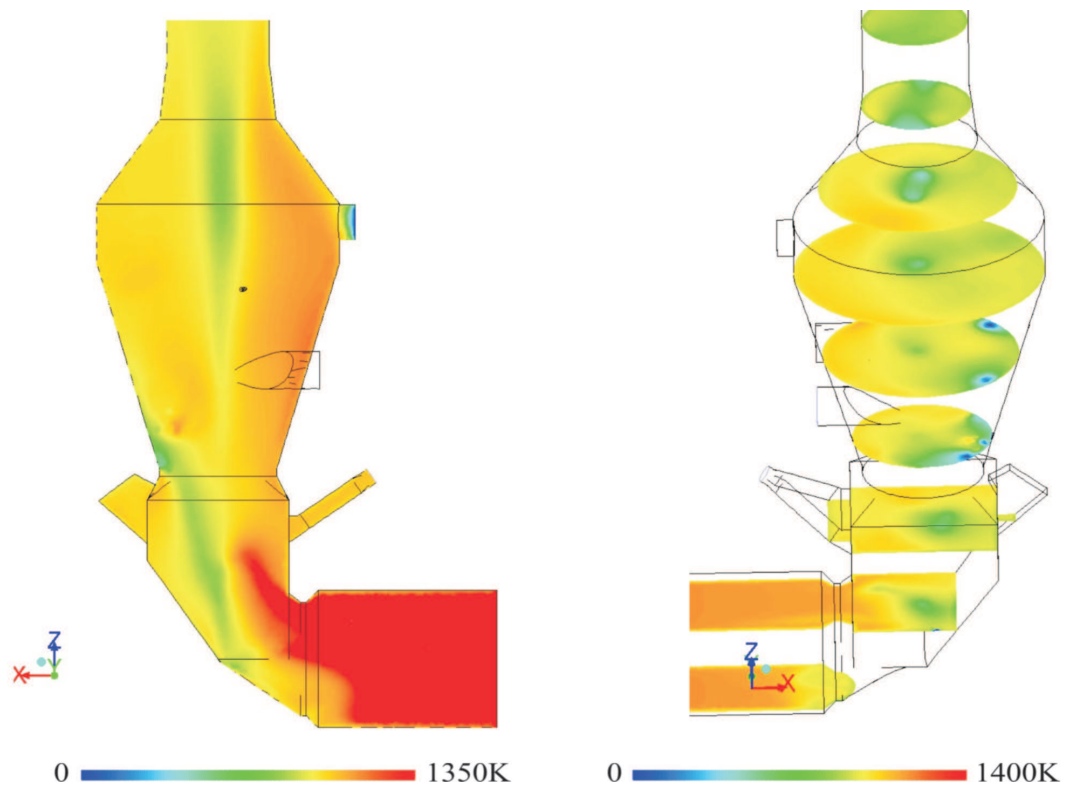

Figure 4: Temperature distribution in precalciner chamber for two ranges of temperature.

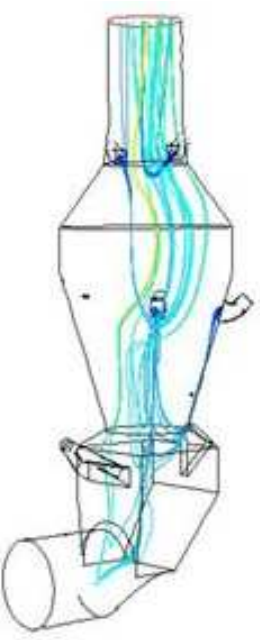

a)

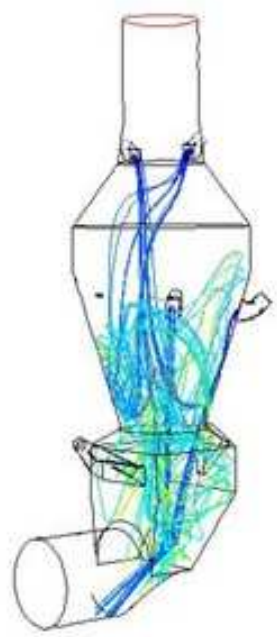

b)

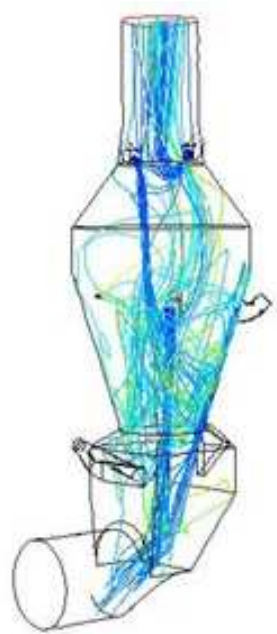

c)

Figure 5: Trajectory particles of number: a) P03, b) P18, c) all diameters. 
smallest in the upper outlet. For all particles from the two inlets, mass flow rate is distributed in the ratio $27.01 \%$ to $72.99 \%$ for the upper and lower outlets, respectively. In Fig. 5 can be seen that the particles are concentrated in small areas in the center of geometry and close to the wall of the chamber. This is due to the fact that almost all of the particles from the lower inlet flow down along the chamber wall in the form of 'rope' and get into a lower outlet, which results in free motion of the gas phase $[18,19]$.

Further analysis of the presented case allows the assessment of certain dependence more accurately than with the enclosed drawings. Analyzing raw material flow rate and fractions through the upper and lower outlets it can be seen that the particle fraction P01-P03 goes entirely through the upper one. Particles P04 in a 93\% goes to the upper outlet. Fraction of particles P08 goes mostly to the outlet of the kiln chamber at a bottom. In total, the upper outlet goes to $27.01 \%$, and $72.99 \%$ to the lower, which is consistent to the experimental results. Presented results are good base to further works on the formation and emission of pollutants especially $\mathrm{NOx}$ and $\mathrm{CO}_{2}$ to atmosphere. Additional aim of the future works ought to be investigation of the heat and mass transfer during thermal decomposition of a single solid particle of raw lime material [20]. In order to implement appropriate conditions it is required to incorporate appropriate procedures in the form of so-called user-defined functions (UDF) in Fluent $[17,21]$.

Comparison of Figs. 3 and 6 leads to the conclusion that in areas with larger particle concentration gas velocity is smaller due to the blocking of these areas. Comparison of Fig.4 and 6 leads to the conclusion that in areas with larger particle concentration gas temperature is smaller due to the more intensive radiative heat exchange between gas and particles in these areas.

Table 3 shows the average residence time of the particles and normalized temperature differences for each fraction in the precalciner chamber. For particles that reach the lower section of the outlet, it is noted a shortening of the residence time with increasing particle size. The residence time in the chamber of the particles P09 from cyclones III reaching the upper outlet cross-section exhibits a maximum.

Particles P01-P03 reach the upper section from cyclone III and have the shortest residence time in the chamber. Due to the fact that the particles get to the areas with high-speed values in the vertical direction, the path between the inlet and outlet are the shortest. The temperature difference between the temperature of the outlet section and the raw material chute 

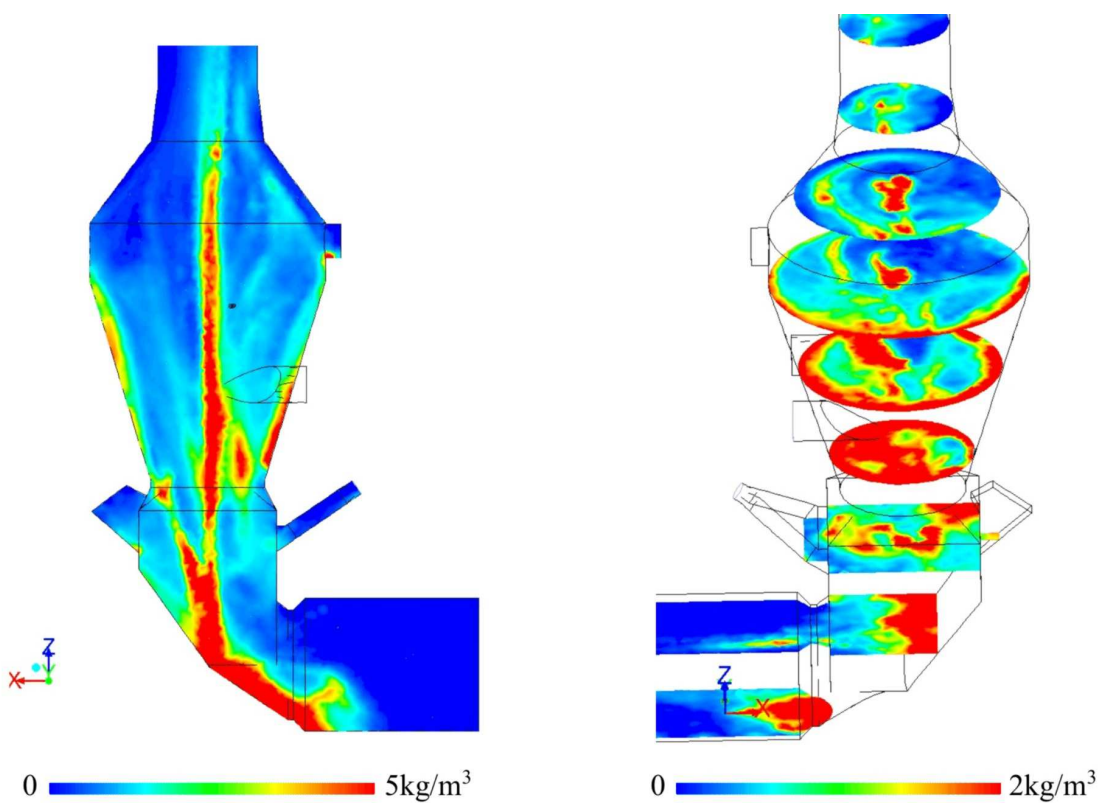

Figure 6: Particles concentration distribution in precalciner chamber for two ranges of concentration.

section was normalized relative to the temperature of $1100 \mathrm{~K}$. The temperature of the raw material particles of lime supplied with cyclones third degree was $1000 \mathrm{~K}$, while the fourth degree of the cyclones was $1100 \mathrm{~K}$. The particles reaching the lower section of the exhaust heat more effectively than others.

\section{Conclusions}

At an early stage of the study, authors found that the particle diameter distribution obtained from the sieve analysis used as one of the conditions for modeling gives a completely incorrect distribution of the mass in the lower and upper outlet of the precalciner in rotary kiln system. Authors found that incorrect distribution is the result of a conglomeration of particles of lime raw material, which is formed by a high temperature in the flow system. This has created a need to solve the inverse problem, which aimed at selecting a proper distribution of particle diameters. The number of numerical calculations used at this stage gave the effect of the mass distribution between top and bottom of the chamber similar to the obtained 
Table 3: Residence time and normalized temperature difference of particles from III and IV cyclones reach the upper and lower outlet sections.

\begin{tabular}{|c|c|c|c|c|c|c|c|c|}
\hline \multirow{2}{*}{ No. particle } & \multicolumn{3}{|c|}{ Particles residence time in chamber [s] } & \multicolumn{3}{|c|}{ Normalized temperature increase [\%] } \\
\cline { 2 - 10 } & from cyclone IV & \multicolumn{2}{|c|}{ from cyclone III } & \multicolumn{2}{|c|}{ from cyclone IV } & \multicolumn{2}{|c|}{ from cyclone III } \\
\cline { 2 - 10 } & upper & lower & upper & lower & upper & lower & upper & lower \\
\hline \hline P01 & 5.00 & - & 1.54 & - & 15.55 & - & 15.34 & - \\
\hline P02 & 6.11 & - & 1.43 & - & 15.33 & - & 15.23 & - \\
\hline P03 & 9.81 & - & 1.62 & - & 15.42 & - & 15.12 & - \\
\hline P04 & 11.14 & 9.95 & 2.88 & - & 15.27 & 17.58 & 15.15 & - \\
\hline P05 & 26.98 & 12.89 & 7.09 & - & 15.26 & 17.69 & 15.18 & - \\
\hline P06 & 19.60 & 8.49 & 6.31 & - & 15.33 & 17.16 & 15.17 & - \\
\hline P07 & 34.92 & 7.82 & 8.30 & 16.40 & 15.47 & 16.97 & 15.28 & 18.39 \\
\hline P08 & - & 7.84 & 14.87 & 22.79 & - & 16.50 & 15.24 & 17.88 \\
\hline P09 & - & 7.76 & 17.08 & 19.37 & - & 16.09 & 15.12 & 17.47 \\
\hline P10 & - & 5.75 & 12.78 & 15.60 & - & 15.73 & 15.06 & 17.21 \\
\hline P11 & - & 5.30 & 12.30 & 16.46 & - & 15.59 & 15.12 & 16.90 \\
\hline P12 & - & 5.14 & 13.07 & 13.80 & - & 15.92 & 15.15 & 16.72 \\
\hline P13 & - & 4.25 & 9.01 & 10.60 & - & 15.64 & 15.10 & 16.62 \\
\hline P14 & - & 3.14 & 2.94 & 11.07 & - & 14.79 & 15.15 & 16.49 \\
\hline P15 & - & 2.80 & 2.26 & 9.10 & - & 13.05 & 15.06 & 16.31 \\
\hline P16 & - & 2.75 & 2.77 & 7.10 & - & 11.42 & 14.99 & 16.28 \\
\hline P17 & - & 2.68 & - & 6.65 & - & 8.61 & - & 16.23 \\
\hline P18 & - & 2.28 & - & 4.56 & - & 1.44 & - & 15.08 \\
\hline
\end{tabular}

from the experimental observations. In order to achieve the separation of the particles mass flow in the correct proportions, authors made series of numerical calculations, for which the fractional distribution of the particles was modified. By scaling the particle diameters it could be observed, that mass flow rate reaching directly to the kiln and returning to the heat exchangers tower were significantly changed. After changing the range of diameters to $15-2900 \mu \mathrm{m}$, large diameter particles fall into the rotary kiln, while the remaining fractions are carried away to the outlet from the chamber. Authors conclude that finding diameter distribution is required in order to obtain the separation of the mass between the top and bottom outlet of the precalciner at a ratio of $30 / 70 \%$. The article presentes real particle diameters and mass flow rates for correct distribution, which was used on the final stage of calculations. Moreover temperature of the parti- 
cle, which is a function of ambient temperature and the residence time of the particles in the zones of sufficiently high-temperature influence on the limestone calcination effectiveness. Obtained results present possibilities of numerical calculations to recognize resident time of particle in precalciner chamber and particle temperature as an effect of radiative hest exchange between gas and limestone particles.

Received 23 June 2015

\section{References}

[1] Saidura R., Hossaina M.S., Islama M.R., Fayazb H., Mohammed H.A.: A review on kiln system modeling. Renew. Sust. Energ. Rev. 15(2011), 5, 2487-2500.

[2] Fidaros D.K., Baxevanou C.A., Dritselis C.D., Vlachos N.S.: Numerical modelling of flow and transport processes in a calciner for cement production. Powder Technol. 171(2007), 2, 81-95.

[3] Hu Z., Lu J., HuAng L., WANG S.: Numerical simulation study on gas-solid twophase flow in pre-calciner. Commun. Nonlinear Sci. 11(2006), 3, 440-451.

[4] Stoyan D., Wuibull: RRSB or extreme-value theorists? Metrika, 76(2013), 2, 153-159.

[5] Apte S.V., Maheshy K., Lundgrenz T.: A Eulerian-Lagrangian model to simulate two-phase/particulate flows. In: Center for Turbulence Research, Annual Research Briefs (2003), 161-171.

[6] Kosinski P., Kosinska A., Hoffmann A.C.: Fluid-particle flows in a driven cavity. In: Proc. Int. Conf. of Numerical Analysis and Applied Mathematics ICNAAM $-2006,1-4$.

[7] Kosinski P., Hoffmann A.C.: An extension of the hard-sphere particle-particle collision model to study agglomeration. Chem. Eng. Sci. 65(2010), 10, 3231-3239.

[8] Widhalm M.: Lagrangian trajectory simulation of rotating regular shaped ice particles. SAE Tech. Paper 2015-01-2141, 2015, doi:10.4271/2015-01-2141.

[9] Wydrych J., Borsuk G., Dobrowolski B., G.Nowosielski: Numerical modelling of gas-particle countercurrent flow in the installation for clinker production. In: Proc. 8th Int. Conf. on Inverse Problems in Engineering, 12-15 May 2014, Kraków.

[10] Borsuk G, Dobrowolski B. Wydrych, J.: Gas-solids mixture flow through a two-bend system. Chem. Process Eng. 27(2006), 3/1, 645-656.

[11] Wydrych J.: Comparative analysis of the methods of simulation of flow in boiler dust systems. Chem. Process Eng. 31(2010), 4, 603-623.

[12] Fidaros D.K., Baxevanou C.A., Dritselis C.D., Vlachos N.S.: Numerical modelling of flow and transport processes in a calciner for cement production. Powder Technol. 171(2007), 2, 81-95. 
[13] Krysiński T., Buliński Z., NowAK A.J.: Numerical modeling and preliminary validation of drag-based vertical axis wind turbine. Arch. Thermodyn. 36(2015), 1, 19-38.

[14] Mujumdara K.S., Ganesha K.V., Kulkarnia S.B., Ranade V.V.: Rotary Cement Kiln Simulator (RoCKS): Integrated modeling of pre-heater, calciner, kiln and clinker cooler. Chem. Eng. Sci. 62(2007), 9, 2590-2607.

[15] GöBel F., MundT C.: Implementation of the P1 radiation model in the CFD solver $N S M B$ and investigation of radiative heat transfer in the SSME main combustion chamber. In: Proc. 17th AIAA Int. Space Planes and Hypersonic Systems and Technologies Conference, (2011).

[16] Mikulcic H., von Berg E., Vujanovic M., Priesching P., Perkovic L., TATSCHL R., DUIC N.: Numerical modeling of calcinations reaction mechanism for cement production. Chem. Eng. Sci. 69(2012), 1, 607-615.

[17] ANSYS Fluent, Release 14.0, ANSYS Inc.

[18] Bilingen H., Levy E.K.: Mixing and dispersion of particle ropes in lean phase pneumatic conveying. Powder Technol. 119(2001), 2-3, 134-152.

[19] Yilmaz A., Levy E.K.: Formation and dispersion of ropes in pneumatic conveying. Powder Technol. 114(2001), 1-3, 168-185.

[20] WARDACh-ŚWIĘCICKA I., KARDAŚ D.: Modeling of heat and mass transfer during thermal decomposition of a single solid fuel particle. Arch. Thermodyn. 34(2013), 2, $53-71$.

[21] KRAWCZYK P., BADYDA K.: Two-dimensional CFD modeling of the heat and mass transfer process during sewage sludge drying in a solar dryer. Arch. Thermodyn. 32(2011), 4, 3-16. 